\title{
Evaluation of hazard distribution in network structures
}

\author{
J. Augutis ${ }^{1,2}$, R. Krikstolaitis ${ }^{1,2}$, V. Matuzas ${ }^{1}$ \& E. Uspuras ${ }^{1}$ \\ ${ }^{1}$ Lithuanian Energy Institute, Lithuania \\ ${ }^{2}$ Vytautas Magnus University, Lithuania
}

\begin{abstract}
The subject of this work is the analysis of hazard distribution in the network systems. In the age when transport flows in the railway and road systems, information flows in the internet channels, etc. the intensity and hazard distribution in the network systems becomes a more relevant and important issue.

In this paper various theoretical hazard type distributions in the network systems are analysed. A mathematical model of hazard distribution and accumulation in the nodes of the network was created. Theoretical results are illustrated by simulation of hazard fuel transportation on Lithuanian roads. It is shown that using this methodology it is possible to construct an algorithm, which enables one to operate and decrease fuel transportation hazard and risk.
\end{abstract}

Keywords: hazard, distribution, risk assessment, network systems.

\section{Introduction}

Hazard in risk analysis is defined as a feature or characteristic of material, technological process, information, human activities or other phenomena that specifies a potential possibility of endangering human life, health, nature, buildings, equipment, etc. Some illustrations of hazards could be poisonous chemical substances kept in stock, open source of radiation, a car with brakes that are out of order, a lock that is built on a river that flows through a city, etc.

In this work we will use numerical values for the hazard, such as the quantity of poisonous materials, the quantity or flow of hazardous information, etc. calling these characteristics hazard level or, in some cases, simply hazard. 
Development and expansion of various networks and network structures creates favourable conditions for the spread of hazard through network channels. One of the most visible examples of such phenomena is the spread of computer viruses in the internet network. It seems that a similar situation is developing in the networks of mobile connection as well. It is also obvious that together with the improvement of means of transportation and the increase in quantity and size of loads, the assessment of hazard distribution becomes more prominent in the systems of transportation.

In the context of this work, hazard is understood as the amount of hazardous materials, the flow of hazardous information, disease concentration, etc. Hazard can be distributed through the channels of various networks and concentrated in the nodes of the networks. Hazard transmission through the channels that connect network nodes can take place in many ways: for example, hazard can be transmitted to a single or to several nodes, as an undivided value or divided into parts. Each node can also have certain protection or immunity against hazard which blocks its transmission or diminishes it.

In all the cases, for hazard distribution in network nodes, iterative equations were made and theorems that describe the sufficient convergence conditions for these processes were proven. For the calculation of the marginal distributions, systems of linear equations were made. To illustrate the theoretical findings, software was created and numerical examples were given.

A hazard assessment model was used to evaluate the risk of fuel transportation on Lithuanian roads.

\section{Marginal distribution of the infinitive source of the hazard in the network nodes with immunity}

In the majority of real network systems, hazard in its whole or in part is eliminated during certain times in a number of cycles. For example, in the computer networks, antivirus systems that destroy the majority of viruses are implemented, human immune system destroys disease viruses, customs does not allow free movement of prohibited goods, etc.

Of course, if the source of the hazard in such systems was a point source (single), the hazard would be entirely destroyed or minimized to the secure level by the system during certain period of time or after a certain number of cycles. In the real systems, however, sources of hazard are often inexhaustible, i.e. infinitive and, at the beginning of every cycle, the hazard can renew. Despite the effort of software developers to fight computer viruses, there are still many hackers that create them and the number of new viruses is not decreasing. Advanced technologies that are used nowadays do not decrease the amount of fake documents and money in the networks of banks and supermarkets.

In this work we will analyse only the marginal hazards in different network systems with the infinitive hazard sources and node immunities.

The immunity of the network node $i$ is considered the number $I_{i}\left(0 \leq I_{i} \leq 1\right)$, by which the hazard $H$ that occurs in this node is multiplied. Thus, when $I_{i}=1$, 
hazard is fully transmitted (such networks have been analysed so far), and when $I_{i}=0$, all of the hazard that makes way to the node $i$ is destroyed. Let network flow matrix will be marked as follows

$$
Q=\left\lfloor q_{i j}\right\rfloor, \text { where } i, j=1,2, \ldots, N \text {. }
$$

Let us assume that the first node of the network is the infinitive source of hazard that increases hazard by the value $H$ during each new cycle. First we shall make an assumption that a marginal hazard distribution exists under such conditions, i.e.

$$
\lim _{n \rightarrow \infty} H_{i}(n)=H_{i}, \text { where } i=1,2, \ldots, N
$$

Then, if at the end of each cycle the hazard that is located in the node is multiplied by the immunity $0<I_{i} \leq 1$, and the node in which the source of hazard is located does not have immunity (let's say it is the first one), in this case hazard in the first node will not change, if it is reduced by the value $H$ after each cycle, i.e.

$$
H_{2} q_{21}+H_{3} q_{31}+\ldots+H_{N} q_{N 1}=H_{1}\left(q_{21}+q_{13}+\ldots+q_{1 N}\right)-H
$$

In the second node, the incoming hazard multiplied by the immunity $I_{2}$ has to be equal to the outgoing hazard. Thus,

$$
I_{2}\left(H_{1} q_{12}+H_{3} q_{32}+\ldots+H_{N} q_{N 2}\right)=H_{2}\left(q_{21}+q_{23}+\ldots+q_{2 N}\right) .
$$

The case in analogous with the other nodes:

$$
\begin{aligned}
& I_{j}\left(H_{1} q_{1 j}+H_{2} q_{2 j}+\ldots+H_{i-} q_{i-1 j}+H_{i+1} q_{i+1 j}+\ldots+H_{N} q_{N j}\right) \\
& =H_{i}\left(q_{i 1}+q_{i 2}+\ldots+q_{i N}\right), \quad j=2,3, \ldots, N
\end{aligned}
$$

Joining those equations we get a system of linear equations:

$$
\left\{\begin{array}{l}
H_{2} q_{21}+H_{3} q_{31}+\ldots+H_{N} q_{N 1}-H_{1} \widehat{q}_{1}=-H \\
H_{1} q_{12}+\ldots+H_{N} q_{N 2}-H_{2} \hat{q}_{2} / I_{2}=0 \\
\cdots \\
H_{1} q_{1 N}+\ldots+H_{N-1} q_{N-1 N}-H_{N} \widehat{q}_{N} / I_{N}=0
\end{array}\right.
$$

The main matrix of this system is: 
366 Risk Analysis V: Simulation and Hazard Mitigation

$$
\widetilde{Q}=\left[\begin{array}{ccccc}
-\widehat{q}_{1} & q_{21} & q_{31} & \ldots & q_{N 1} \\
q_{12} & -\hat{q}_{2} / I_{2} & q_{32} & \ldots & q_{N 2} \\
\ldots & \ldots & \ldots & \ldots & \ldots \\
q_{1 N} & q_{2 N} & q_{3 N} & \ldots & -\widehat{q}_{N} / I_{N}
\end{array}\right]
$$

constants vector $\bar{B}=\left[\begin{array}{lllll}-H & 0 & \ldots & 0\end{array}\right]^{T}$, and unknowns vector $\bar{H}=\left[\begin{array}{llll}H_{1} & H_{2} & \ldots & H_{N}\end{array}\right]^{T}$.

Thus, this system can be written in the form of matrix

$$
\widetilde{Q} \bar{H}=\bar{B}
$$

To investigate the existence of the marginal distribution, hazard distribution $\vec{H}(n)$ will be expressed in such iterative process:

$$
\vec{H}(n+1)=\vec{H}(n) \cdot Q
$$

As there is the immunity, we shall introduce a diagonal matrix

$$
I=\left[\begin{array}{cccc}
I_{1} & 0 & 0 & 0 \\
0 & I_{2} & 0 & 0 \\
\cdots & \cdots & \cdots & \cdots \\
0 & 0 & 0 & I_{N}
\end{array}\right]
$$

Now we can express the system of equations this way:

$$
\begin{gathered}
{\left[H_{1}(n+1), H_{2}(n+1), \ldots, H_{N}(n+1)\right]=\left[H_{1}(n), H_{2}(n), \ldots, H_{N}(n)\right] \times I \times Q+[H, 0, \ldots, 0]} \\
Q=\left[\begin{array}{cccc}
q_{11} & q_{12} & \ldots & q_{1 N} \\
q_{21} & q_{22} & \ldots & q_{2 N} \\
\ldots & \ldots & \ldots & \ldots \\
q_{N 1} & q_{N 2} & \ldots & q_{N N}
\end{array}\right]
\end{gathered}
$$

We mark $\vec{H}(n)=\left[\begin{array}{llll}H_{1}(n) & H_{2}(n) & \ldots & H_{N}(n)\end{array}\right]^{T}, \vec{H}(0)=\left[\begin{array}{llll}H & 0 & \ldots & 0\end{array}\right]^{T}$ and obtain that

$$
\vec{H}(n+1)=\vec{H}(n) \cdot I \cdot Q+\vec{H}(0)
$$


In the paper the convergence conditions of the process (4) were not fully set; however, for this process, general condition that is necessary and sufficient for the convergence of iterative processes applies: for the process (4) to converge, it is necessary and sufficient that all the absolute values of the $I \cdot Q$ matrix are less than $1[7]$.

\section{Hazard assessment of oil products transportation in Lithuanian roads}

As an example of the marginal distribution of the infinitive source of hazard, we will analyse the hazard of the fuel transportation in Lithuanian roads in two way: analytical calculation using (2) equation system and computer simulioation using (4) iterative process. Fuel transportation from the "Mažeikių nafta" refinery terminal to the biggest city of Lithuania Vilnius was investigated. All possible and most probable routes are presented in Fig. 1.

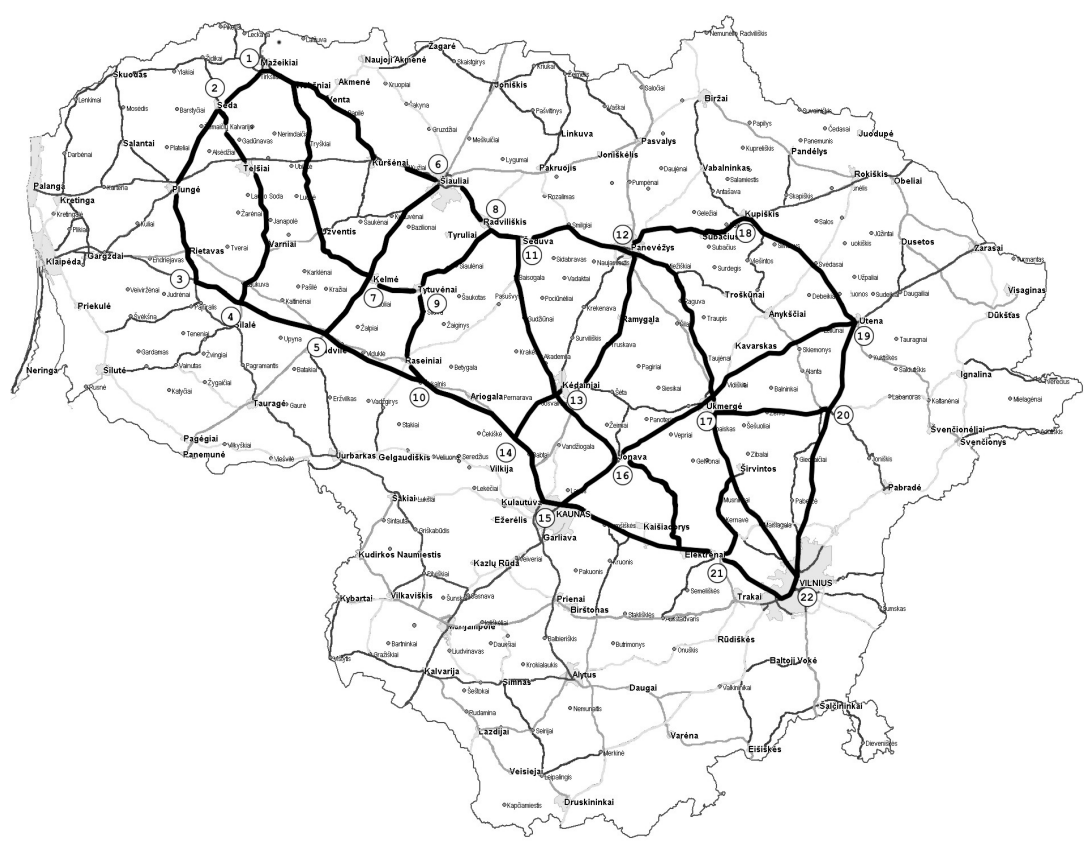

Figure 1: Lithuanian roads graph.

For the analysis, an oriented graph with 22 nodes and 72 links was chosen. In this case, Lithuanian towns constituted a set of nodes and the network of Lithuanian roads - a set of links. The immunities of all the nodes, except for Vilnius, were equal to 1 , as we were interested in hazard distribution from the initial node Mažeikiai to the final node Vilnius. The source of hazard (Mažeikiai) during each cycle is supplemented with a relative hazard unit, which is equal to 1 
$(H=1)$. Since the hazard is generated during each cycle, in some nodes total hazard can exceed 1.

Using (2) equation system the following solution is obtained:

Table 1: Hazard distribution in Lithuanian roads (analytical calculations).

\begin{tabular}{|l|l|l|l|l|c|}
\hline Node name & No. & Hazard level & Node name & No. & Hazard level \\
\hline Mažeikiai & 1. & 1.0733 & Panevéžys & 12. & 0.2711 \\
\hline Seda & 2. & 0.3664 & Kėdainiai & 13. & 0.3248 \\
\hline Rietavas & 3. & 0.2568 & Cinkiškės & 14. & 0.8419 \\
\hline Kryžkalnis & 4. & 0.3735 & Kaunas & 15. & 1.0695 \\
\hline Skaudvilė & 5. & 0.6486 & Jonava & 16. & 0.3455 \\
\hline Šiauliai & 6. & 0.6083 & Ukmerge் & 17. & 0.3449 \\
\hline Kelmė & 7. & 0.4922 & Kupiškis & 18. & 0.0592 \\
\hline Radviliškis & 8. & 0.4491 & Utena & 19. & 0.0997 \\
\hline Tytuvėnai & 9. & 0.3017 & Molètai & 20. & 0.1796 \\
\hline Raseiniai & 10. & 0.8347 & Elektrėnai & 21. & 0.8730 \\
\hline Šeduva & 11. & 0.4693 & Vilnius & 22. & 0.2083 \\
\hline
\end{tabular}

As we see from the table, the highest hazard, when transporting fuel by the route Mažeikiai - Vilnius, is in Kaunas and in the source of hazard (Mažeikiai). The reason why Kaunas has the highest level of hazard is that it is a relative centre of the network of Lithuanian roads [6], [10].

The hazard was also estimated using equation (4). Modelling results are given in Table 2. The results that were presented are settled after 20000 iterations. As we can see, results are almost the same in both cases. It means that for large systems we can use modelling, because analytical solution is becoming complicated.

Table 2: $\quad$ Hazard distribution in Lithuanian roads (computer simulation).

\begin{tabular}{|l|l|c|l|l|c|}
\hline Node name & No. & Hazard level & Node name & No. & Hazard level \\
\hline Mažeikiai & 1. & 1.0695 & Panevėžys & 12. & 0.27315 \\
\hline Seda & 2. & 0.3626 & Kèdainiai & 13. & 0.32465 \\
\hline Rietavas & 3. & 0.2529 & Cinkiškès & 14. & 0.84495 \\
\hline Kryžkalnis & 4. & 0.3656 & Kaunas & 15. & 1.0728 \\
\hline Skaudvilė & 5. & 0.6376 & Jonava & 16. & 0.33955 \\
\hline Šiauliai & 6. & 0.6047 & Ukmergè & 17. & 0.35705 \\
\hline Kelmė & 7. & 0.4823 & Kupiškis & 18. & 0.0622 \\
\hline Radviliškis & 8. & 0.447 & Utena & 19. & 0.0841 \\
\hline Tytuvėnai & 9. & 0.2932 & Molètai & 20. & 0.1515 \\
\hline Raseiniai & 10. & 0.8265 & Elektrènai & 21. & 0.85115 \\
\hline Šeduva & 11. & 0.46825 & Vilnius & 22. & \\
\hline
\end{tabular}




\section{Conclusions}

The main aim of the paper is to present the developed hazard distribution mathematical model and its analysis. Here was analysed the mechanism of hazard propagation in network systems in the case when hazard arise during each cycle. The most important cases are hazard propagation in Markov chains and network systems, where peaks have an immunity or resistance to the hazard characteristic.

From the material presented in the paper we can see that marginal hazard distribution network system can be determined as linear equation system.

In the paper illustration of the results applicability is presented. Based on the marginal hazard distribution mathematical model the hazard caused by fuel transportation by fuel trucks was estimated in the fragment of Lithuanian roadway network.

\section{References}

[1] Lefevre C, Picard P (1993) An Epidemic Model with Fatal Risk, Mathematical Biosciences, New York, 117:127-145 p.

[2] Purdy G (1993) Risk analysis of the transportation of dangerous goods by road and rail, Journal of Hazardous Materials, 33, p.229-259.

[3] Gnedenko B, Pavlov IV, Ushakov I, Chakravarty A (1999) Statistical Reliability Engineering, New York, NY: John Wiley \& Sons.

[4] Kleinrock L and Gail R. (1996) Queuing Systems: Problems and Solutions, John Wiley \& Sons.

[5] Chapra SC and Canale RP (2001) Numerical Methods for Engineers: With Software and Programming Applications McGraw-Hill Science/Engineering/Math Date Published.

[6] Augutis J, Krikštolaitis R, Matuzas V, Ušpuras E (2005) Risk of oil products transportation in Lithuania, Proceed. Of the International Topical Meeting on Probabilistic Safety Analysis. San Francisco, ISBN: 0-89448$690-\mathrm{X}$

[7] Rosen K (1998) Applications of Discrete Mathematics, 4th ed. New York: McGraw-Hill.

[8] Roeleven D, Kok M, Stipdonk HL, de Vries WA Inlan (1995) Waterway transport: Modelling the probability of accidents. Safety Science. Volume 19, 191-202 p.

[9] Adams J (1995) Risk, London: UCL Press Ltd.

[10] Volkovas V, Krikštolaitis R, Matuzas V, Doroševas V, Augutienė E. (2005) Risk Analysis of Petrol Transportation. Environmental research, engineering and management. Kaunas, No.1(31), P.45-54. 